\title{
STUDY ON ROAD SAFETY IMPROVEMENT IN INDIA
}

\author{
Vigneshkumar $\mathrm{K}^{1}$, P.Vijay ${ }^{2}$ \\ ${ }^{I}$ Student, Department of mechanical engineering, Knowledge institute of technology, Tamilnadu, India \\ ${ }^{2}$ Assistant professor, Department of mechanical engineering, Knowledge institute of technology, Tamilnadu, India
}

\begin{abstract}
Road safety management is a major concern in India. Now a day's roads are the highly hazardous environment in India. Road safety management reduces the injuries fatalities and major accidents. For every road the accidents are reported and collect the relevant data about the accidents are reported and review the collected data about the accident should be recorded. Based on the details and reports the implementation of remedial measures also not possible because of less available data. The analysis are made depends upon the record to find out the high risk location, vulnerable road users. The reasons for accident is "Unsafe Conditions or Unsafe Acts" either by the road or by the drivers. This study highlighting the lack of road safety awareness for the public, drivers and the basic concepts for improving the road safety management in India
\end{abstract}

Keywords: Road safety, accident, and etc...

\section{INTRODUCTION}

Total networks of roads in India are 47lakh KM. The roads are classified under four categories 1) National highways, 2) state highways;3) PWD roads; 4) Rural and other roads. The distance of national highways is 70934KM, State highways $1,63,896 \mathrm{KM}$, The distance of PWD Roads is $10,05,327 \mathrm{KM}$ Rural and other roads are 27,49,805KM. For every $1 \mathrm{~min} 1$ major accident occurs, at least 1 accident death for every 1 min. (Road Accidents in India,2010) Ministry of Road Transport and Highways. The road accidents in India nearly 4 to 5 lakhs the accident rate is gradually increasing every year.

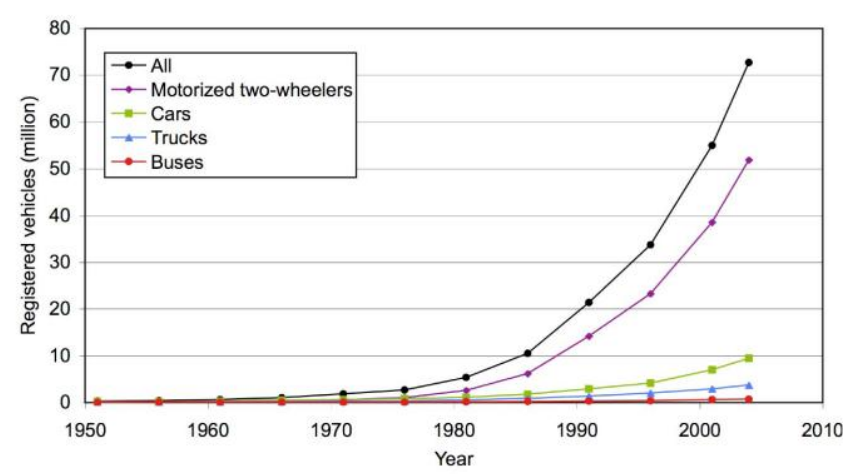

Registered vehicles 1951 through 2005(Department of Road and Transport)

The vehicles registered in India from 1951 to 2005 was $3,00,000$ to $75,00,000$. An accident is an incident that happens unexpectedly and unintentionally. It is occasioned either by human failure or human negligence. Viewed from the above perspective and also thorough hindsight every road accident is an avoidable happening. The history of human kind has been one of conquests over the inevitable. It is the process of development and the absence of significant and meaningful results from the issues. Having considered all the relevant facts and also the suggestions that have come from the different quarters it appears to us that the four dimensional approach that had earlier attempted by setting up four different working groups to go into the four issues of road safety namely, engineering, enforcement, education and emergency care would be the best manner to approach the issues arising. In the aforesaid publication in which the relevant figures are pegged to the year i.e. 2010 numbered nearly 5, 00,000 resulting in approximately 1, 30,000 deaths and serious injuries including amputation of limbs to over5,00,000 persons. Road accidents therefore to have potential of being one of the largest challenges to orderly human existence necessitating immediate and urgent intervention. The feature of vehicles about $10 \%$ of all the road accidents; $30 \%$ of the accidents is related to characteristics of road such as pathway (about 10\%), geometry level $(10 \%)$ and the other factors (safety barriers, guardrails, signal.)(Variana rosoline et al 2014).The recent development technologies in mobile communication allows a continual monitoring of drivers behavior by means of acceleration, speed, acceleration rate of the vehicles and data collection of service record (Astarita et al.,2012)

\section{ROAD SAETY}

The approach for road safety management is suggest some measures to reduce the accidents and to be implemented in the different classification of road networks for minimize the accidents, injuries, fatalities and damage to the properties result of road accidents table 1. Shows the brief work for good road safety development. The road traffic is also one of the most important issues in the road safety management. The accident factor in the behavior of human is very high. The basic concept of safety is the road safety audits, inspections and black spot managements was developed and promoted by (Perandones and Ramos, 2008). The efforts which are al completely eliminated in the transportation risk and it's contribute a reduction of risk and to minimize the crashes level and consequences 


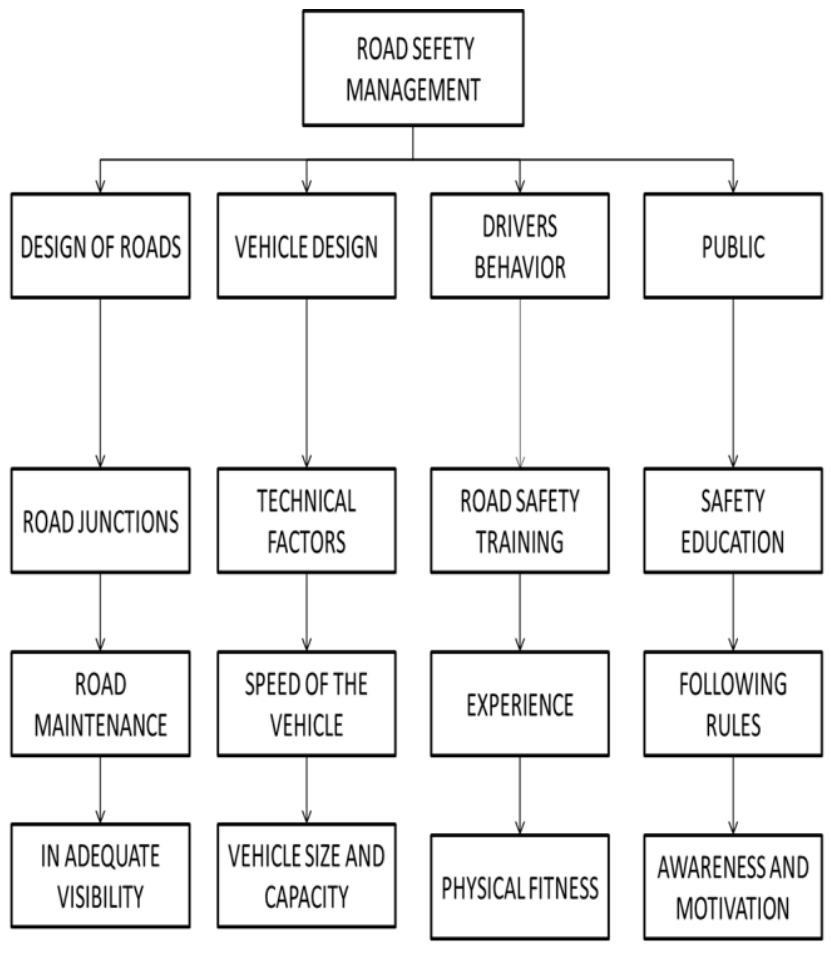

\section{DESIGN OF ROADS}

In India the road networks are nearly 47 lakh KM. The roads are properly design with safety aspects but accident rate of the roads accidents are merely increased as to the extent. Designs of roads are classified as three types 1) Road junctions 2) Road maintenance 3) Inadequate visibility. Roads design depends on the location of the road, traffic congestion, Hospital areas and educational institutions, road dividers and road junctions. And also the analyzing of accident reports is also useful for design of safe roads.

\subsection{Road Junction}

In Tamilnadu the road junction between state highway to national highway, rural roads to national highways, rural roads to state highways, national highways to national highways. The view of the junctions should be very clear to the drivers likewise the road should be designed. The speed of the vehicle will be reducing by various techniques like speed prediction models, speed separators, speed dividers are to be use in the junction areas. Pedestrian crossing for the public are properly depends on the congestion rate. Every roads and junctions signs and symbols in the state are should in the same manner and also reflecting stickers are used in the night driving, it helps to the aware the drivers about the junction. Parking of vehicles near the junction is completely restricted, in which helps to made traffic congestion. Lighting level of the junction should be very high.

\subsection{Road Maintenance}

Road maintenance is the effective one in the design of road safety. Every road must be maintained in the period of interval and so the repair works if the roads are damaged or the surface are not clear, un repaired works are the major cause for the major road accidents. So the maintenance should be done for every works such as lightning, traffic signals and the reflectors.Anomalies and irregularities a correlation between the crash rate and road surface like friction and texture. Potholes in the road surface becomes discomfort and risks to the drivers

\subsection{Inadequate Visibility}

The lateral access of road accidents is the direct access to roads can effectively increase accidents; previous studies show the road segment 2 driveways per $\mathrm{km}$. Bituminous roads are classified in the ways of the 1 ) excessive consecutive accesses on the roads, 2) position of accesses in both sides of roads. A traffic signal can be defined as a placed along the attempt to aid or control the driver transmitting an unambiguous, quick and clear message to the road users (Ramos et al 2008).

\section{VEHICLE DESIGN}

The vehicle design also major cause for the accidents and so the design will be the accident free. For ensuring safer public vehicles it has been suggested that the governments of all states a) The width, height and length of vehicles b) the size, nature and condition of wheels and tyres; c) brakes d) lamps and reflectors e) warning devices; f) the inspection of vehicles g) regulating the particulars exhibited on vehicles and the manner in which such particulars shall be exhibited.

\subsection{Technical Factors}

Ground clearance, anti-lock breaking system, airbags, the head lights, ergonomically designed seats and seat belts and diesel tanks.

The ground clearance of the vehicle is must be very clear, the antilock breaking system are the technique which should be adopted for toppling of the vehicle, new trends of technology driver seat vibrator for safe drive if driver sleeps while driving, the seat will be vibrates. Information regarding road safety can be viewed through the use of web portal, at this case referring to a web GIS. On board drivers can be received by real-time messages through smartphones.

\subsection{Speed of the Vehicle}

Speed of the vehicle is most dangerous think for the accidents, the most important factors related to road safety, the measurable parameter can be used for a (Vaiana et al 2014). Using new advanced technologies the speed of the vehicle can be controlled if the vehicle crossed more than $120 \mathrm{~km}$ speed the warning alarm will come and the system engaged to alert the driver about caution of speed.

\subsection{Vehicle Size and Capacity}

The vehicle size and capacity are also leads to accident. increasing of loads than the actual load, it has to chance of fell or topple for the vehicle, extending the length of vehicle from chase, overloading of commercial vehicles should be 
prosecuted under the damage to public property, issue of fitness certificate for commercial vehicles should be based on stringent inspection, traffic violations database should be maintained to record data of violating vehicles, drivers and offences committed.

\section{DRIVERS BEHAVIOUR}

Most of the accidents are caused by drivers behavior because there is a more possibilities of accident, three stages which explaining the drivers behavior 1) Road safety training 2) Experience 3) physical fitness. These are the factors discussing about the behaviors of drivers.

\subsection{Road Safety Training}

Use of road safety devices there should be no exemption for wearing helmets (such as the exemptions in favor of women in some states). Seatbelts should be compulsory for driver and front seat passenger. On national highways, seat belts should be compulsory for back seat passengers too,. In case of drunken driving the norm should be suspension of the driving license and should be strictly enforced by traffic police. Every six months once the drivers should attend the road safety program, the program conducted by the higher professionals to motivate the drivers to know about the recent safety technology aspects.

\subsection{Experience}

The experienced drivers are expert one in driving in some cases the experienced one also cause to do major accidents y because of not aware of new safety aspects of the road structure . for experienced drivers too can attend the safety program to get the knowledge about the safety, in olden there was no rules about safety belts, helmets etc. to update the new trends of safety aspects .

\subsection{Physical Fitness}

Every year the drivers should produce the physical fitness, the licensing method of drivers is to be digitized. Every accident records should be added in the driver license in that case the licensing method is to be updated. Digitization of driving license in the country so that defaulters cannot obtain other licenses (upon cancellation or suspension of their license) physical fitness which include the eye sight and hearing capability. Above 50 years of aged drivers should not allow driving long distances, depends upon the physical fitness the person should allow to drive in local areas. The suggestions which are given to the drivers are effective one and it should be in continuous monitoring.

\section{PUBLIC}

The general public does not possess basic first aid skills. There is no standardized toll free access number to call emergency medical help. Non availability of appropriate and safe transport for injured patient in the form of road ambulances, air ambulances etc. the ambulances are inappropriately inadequately equipped.1) Safety education, 2) Following rules and regulations, 3) General awareness about safety. Majority of the drivers do not have a personal med claim policy to cater to their emergency medical needs in case of accident

\subsection{Safety Education}

Road safety education should be given to the children, students, college teens and the people. Because it gives the motivation to the children and students, if they are start to follow the safety aspects is good for the country growth. The people should obey the rules and regulations of the motor vehicles act.

Most of the road accidents were happened in the road junctions or in the highway crossing areas and in the small road connecting areas. Most of the village people are un aware of the road safety and the road accidents. The repeated accident was happened in any particularly hazardous locations. For this study the case study of the accident were analyzed in shown detail. Salem to Coimbatore highway at sankari-2014 unexpected road accident was happened in that accident 6 people and 1 child was died. The reason for the accident was

1). Over speeding of the vehicle,

2). The driver didn't know the road junction,

3). The driver was sleepy because of long drive,

4). The people was in the vehicle didn't wear the seat belt and

5). There was no sign boards about the road junction.

\section{SUGGESTIONS AND RECOMMENDATIONS}

In recent years people and the drivers are not aware of road safety, the accidents are happening in every second in India. To reduce the accident this study suggested that every road junction and connecting roads signs and symbols should be the same; the speed level of the vehicles should be reduced near junctions using speed prediction models. Drivers should use the indicators while turning lefts and right. Seat belts, helmets should be worn out. The government should undertake road safety trainings to the drivers and it should be a compulsory to the drivers who participated the training and program only allowed to drive with physical fitness certificate.

\section{CONCLUSIONS}

In this study the methodology for evaluating road safety management was accessed and road network improvement techniques are proposed. The safety awareness and training to the public was given. The education, enforcement and the emergency care of the people was trained under this study. Many people are affected from major accidents are reported and recorded for improving the good road safety improvement in India. 


\section{REFERENCES}

[1]. Rakesh Mehar ${ }^{\mathrm{a}},{ }^{1}$ Pradeep Kumar Agarwal'(2013).” A Systematic Approach For Formulation Of A Road Safety Improvement Program In India",Procedia-Social and Behavioral Sciences 104,(1038-1047).

[2]. Variana Rosolino ${ }^{a}$, Iuele Teresa ${ }^{a, *}$, Astarita Vittorio ${ }^{a}$, Festa D. Carmine ${ }^{a}$, Tassitani Antonia ${ }^{a}$, Rogano Daniele ${ }^{\mathrm{a}}$,Zaffino Claudio ${ }^{\mathrm{a}}$,(2014)."Road Safety Performance Assessment: a new road network Risk Index for info mobility"Procedia-Social and Behavioral Sciences 111,(624-633). 